\title{
Colonization and Movement of GFP-Labeled Clavibacter michiganensis subsp. michiganensis During Tomato Infection
}

\author{
L. Chalupowicz, E.-M. Zellermann, M. Fluegel, O. Dror, R. Eichenlaub, K.-H. Gartemann, \\ A. Savidor, G. Sessa, N. Iraki, I. Barash, and S. Manulis-Sasson
}

First, fourth, and eleventh authors: Department of Plant Pathology and Weed Research, ARO, the Volcani Center, Bet Dagan, Israel; second, third, fifth, and sixth authors: Department of Microbiology/Genetechnology, Faculty of Biology, University of Bielefeld, Bielefeld, Germany; seventh, eighth, and tenth authors: Department of Molecular Biology and Ecology of Plants, Faculty of life Sciences, Tel Aviv University, Tel Aviv, Israel; and ninth author: UNESCO Biotechnology Center, Bethlehem University, Bethlehem, Palestinian Authority. Accepted for publication 18 August 2011.

\begin{abstract}
Chalupowicz, L., Zellermann, E.-M., Fluegel, M., Dror, O., Eichenlaub, R., Gartemann, K.-H., Savidor, A., Sessa, G., Iraki, N., Barash, I., and Manulis-Sasson, S. 2012. Colonization and movement of GFP-labeled Clavibacter michiganensis subsp. michiganensis during tomato infection. Phytopathology 102:23-31.

The vascular pathogen Clavibacter michiganensis subsp. michiganensis is responsible for bacterial wilt and canker of tomato. Pathogenicity of this bacterium is dependent on plasmid-borne virulence factors and serine proteases located on the chromosomal chp/tomA pathogenicity island (PAI). In this study, colonization patterns and movement of C. michiganensis subsp. michiganensis during tomato infection was examined using a green fluorescent protein (GFP)-labeled strain. A plasmid expressing GFP in C. michiganensis subsp. michiganensis was constructed and found to be stable in planta for at least 1 month. Confocal laser-

scanning microscopy (CLSM) of inoculated stems showed that the pathogen extensively colonizes the lumen of xylem vessels and preferentially attaches to spiral secondary wall thickening of the protoxylem. Acropetal movement of the wild-type strain C. michiganensis subsp. michiganensis NCPPB382 (Cmm382) in tomato resulted in an extensive systemic colonization of the whole plant reaching the apical region after 15 days, whereas Cmm100 (lacking the plasmids pCM1 and pCM2) or Cmm27 (lacking the chp/tomA PAI) remained confined to the area surrounding of the inoculation site. Cmm 382 formed biofilm-like structures composed of large bacterial aggregates on the interior of xylem walls as observed by CLSM and scanning electron microscopy. These findings suggest that virulence factors located on the chp/tomA PAI or the plasmids are required for effective movement of the pathogen in tomato and for the formation of cellular aggregates.
\end{abstract}

Clavibacter michiganensis subsp. michiganensis is the causal agent of bacterial wilt and canker of tomato. It is the most destructive bacterial disease of tomato worldwide and is subjected to strict national and international quarantines $(11,12)$. Contaminated seed, infected plant residues in the soil, or symptomless Solanum spp. are common sources for $C$. michiganensis subsp. michiganensis inoculum (30). Bacteria enter the host plant via natural openings and wounds. C. michiganensis subsp. michiganensis colonizes primarily the xylem and leads to a systemic infection characterized by unilateral leaf wilting and canker development on the tomato stem that eventually culminates in plant death. The pathogen can survive as an effective endophyte in tomato but apparently has to establish an endophytic population of $>10^{8} \mathrm{CFU} / \mathrm{g}$ of plant tissue in order to induce disease symptoms (15).

The sequenced genome of the wild-type strain $C$. michiganensis subsp. michiganensis NCPPB382 (Cmm382) represents a single circular chromosome of $3.3 \mathrm{Mb}$ with high $\mathrm{G}+\mathrm{C}$ content $(72.6 \%)$. It carries a pathogenicity island (PAI) of $129 \mathrm{~kb}$ with a lower $\mathrm{G}+\mathrm{C}$ content $(65.5 \%)$ designated as the chp/tomA region (14). This PAI can be divided into two subregions: the chp region, which harbors several genes encoding serine proteases, and the

Corresponding author: S. Manulis-Sasson

E-mail address: shulam@volcani.agri.gov.il

* The $\boldsymbol{e}$-Xtra logo stands for "electronic extra" and indicates that the online version contains two supplemental figures. Figures 2 and 7 appear in color online.

http://dx.doi.org/10.1094/PHYTO-05-11-0135

(C) 2012 The American Phytopathological Society
tomA region, which includes tomA, encoding a tomatinase, as well as genes encoding proteins involved in sugar uptake and metabolism (14,19). A chp/tomA PAI deletion mutant (i.e., Cmm27) does not induce disease symptoms and colonizes the tomato xylem at a considerably lower titer than the wild type (4).

Cmm382 harbors two circular conjugative plasmids, pCM1 $(27.4 \mathrm{~kb})$ and pCM2 (70 kb), each of which carries a major virulence gene (24). pCM1 contains celA, encoding an endo- $\beta-1,4-$ glucanase, and pCM2 harbors pat-1, encoding a putative serine protease. Both are involved in the induction of wilting in infected tomato plants $(9,17)$. Curing Cmm382 of either pCM1 (i.e., Cmm102) or pCM2 (i.e., Cmm101) results in a reduction of wilt symptom. The loss of both plasmids (i.e., Cmm100) still allows considerable endophytic growth but leads to lack of symptom induction (15,24). Additionally, Cmm382 secretes a wide range of cell-wall-degrading enzymes (i.e., polygalacturonase, pectate lyases, xylanases, and endoglucanases) and a large group of serine proteases of different families (i.e., Chp, Ppa, and subtilase) (14). These serine proteases were induced in planta and identified in the sap of infected tomato plants, suggesting their involvement in C. michiganensis subsp. michiganensis infection $(2,4)$ (unpublished data).

Development of systemic infections caused by gram-negative vascular plant-pathogenic bacteria has been previously investigated $(6,28)$. These studies were most thoroughly performed with Pantoea stewartii subsp. stewartii, causing wilt and leaf blight in sweet corn $(16,23)$, and Xylella fastidiosa, a host-specific pathogen of grape that causes leaf scorching and berry desiccation $(1,27)$. Other vascular bacteria which have been studied include Erwinia amylovora, the causal agent of fire blight in apple and 
pear (21); Xanthomonas campestris pv. campestris; the causal agent of black rot on crucifer plants (8); and Ralstonia solanacearum, which causes lethal wilt on many plants (18). Common features involved in systemic development and virulence among most of these vascular pathogens are (i) formation of extensive bacterial aggregates and biofilm attached to xylem surfaces, (ii) contribution of exopolysaccharide (EPS) to vascular blockage and symptom development, and (iii) involvement of quorum-sensing (QS) in regulation of xylem colonization (6). In the case of $P$. stewartii subsp. stewartii and Xylella fastidiosa, bacterial motility was also demonstrated to play a crucial role in systemic development and virulence $(16,26)$.

In contrast to the ample information on systemic spreading of vascular gram-negative bacteria, knowledge on the movement characteristics of gram-positive vascular bacteria is very limited. In the case of $C$. michiganensis, it could be assigned to the lack of adequate molecular tools for studying the pathogen in planta. For example, fluorescent reporters, such as the green fluorescence protein (GFP), which are commonly used to track bacteria in infected plants, could not be expressed in $C$. michiganensis. Recently, bioluminescence imaging was employed to follow $C$. michiganensis subsp. michiganensis infection of tomato plants (35). Although the bioluminescence technique provides sensitive detection levels, it depends on the kinetics of cellular uptake of substrates and cannot be used to follow single bacterial cells or detect them in damaged tissue or dead cells (22). To circumvent these limitations, in the present study, we utilized an enhanced (E)GFP bioreporter to examine colonization patterns and movement of $C$. michiganensis subsp. michiganensis in infected tomato plants. To attain this goal, an EGFP reporter that could be ex-

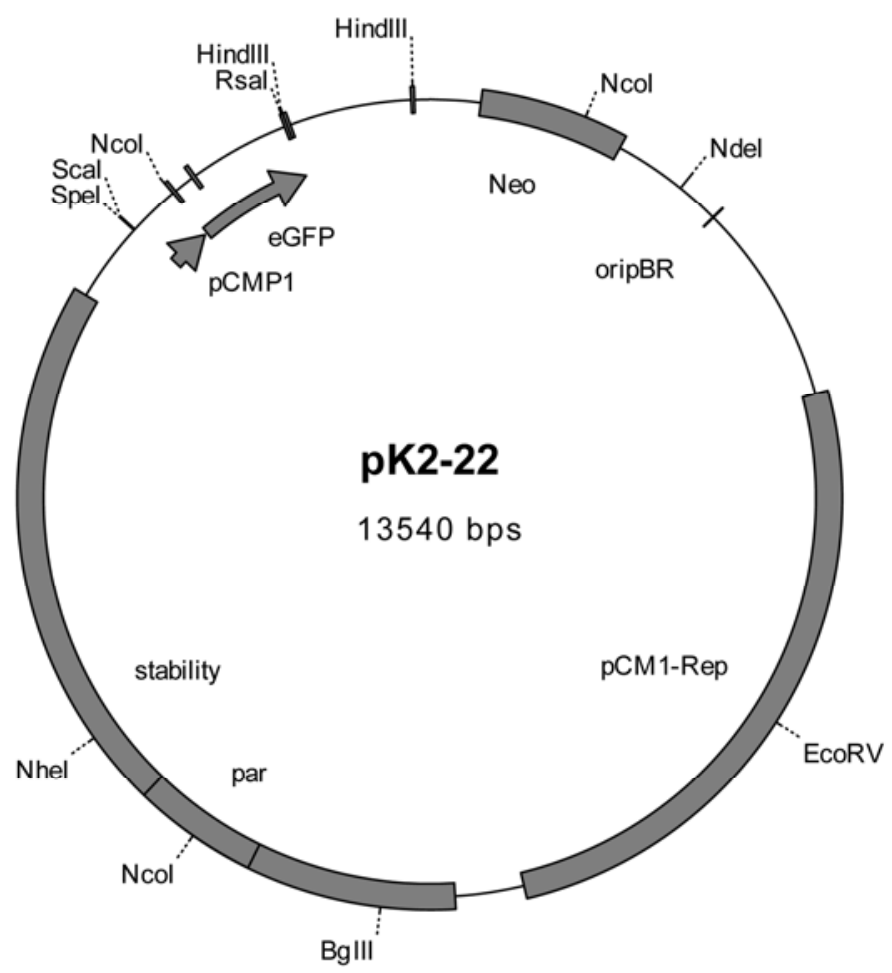

Fig. 1. Physical map of the green fluorescent protein ( $g f p)$-expressing plasmid pK2-22. A 739-bp ScaI DNA fragment carrying the enhanced (e)gfp gene from pGem EGFP was inserted into Clavibacter michiganensis subsp. michiganensis shuttle vector $\mathrm{pDM} 302$. The $S t u \mathrm{I}$ and ribosomal-binding site were artificially generated by cloning annealed oligonucleotides upstream of the start codon of $e g f p$. A 254-bp RsaI DNA fragment (pCMP1) derived from phage CMP1 $(50,302-50,048)$ was then inserted, by blunt-end ligation, into a StuI-predigested plasmid to generate pK2-22. Neo = neomycin phosphotransferase, ori $\mathrm{pBR}=$ origin of replication of the vector $\mathrm{pBR} 322, \mathrm{pCM} 1-\mathrm{Rep}=$ replication region of the plasmid $\mathrm{pCM} 1$, par = partitioning region of $\mathrm{pCM} 1$, stability $=$ region from $\mathrm{pCM} 1$ necessary for stable maintenance of the vector. pressed and stably maintained in C. michiganensis subsp. michiganensis was constructed to allow a direct and precise visualization of fluorescent cells by confocal laser-scanning microscopy (CLSM). This microscopic analysis provides, for the first time, significant insights into the mode of colonization and spatial adherence preferences of $C$. michiganensis subsp. michiganensis during disease development. Moreover, the EGFP-labeled pathogen was utilized to test the hypothesis that virulence factors encoded in the chp/tomA PAI or in the plasmids are important for biofilm formation as well as for acropetal and basipetal movement within the tomato plant. Results of this study shed new light on the essential role of the systemic movement of $C$. michiganensis subsp. michiganensis in pathogenicity.

\section{MATERIALS AND METHODS}

Bacterial strains and growth conditions. The $C$. michiganensis subsp. michiganensis strains used in the present study were the wild-type pathogenic strain NCPPB382 (Cmm382) and its derivatives, $C m m 100$ (lacking the two virulence plasmids pCM1 and pCM2), Cmm101 (lacking pCM2), and Cmm102 (lacking pCM1) (25); Cmm27, a deletion mutant of Cmm382 lacking the chp/tomA region (4); and $C m m c h p C^{-}$, (a mutant in $\operatorname{chpC}$, a gene encoding serine protease located in the $\operatorname{chp} /$ tom $A$ PAI) (29). Depending on the analysis, the $C$. michiganensis subsp. michiganensis strains were grown at $25^{\circ} \mathrm{C}$ for 48 to $72 \mathrm{~h}$ in LuriaBertani (LB) broth or agar (Difco, Le Pont de Claix, France), minimal medium (M9) broth (4), or CNS broth or agar plates (20). When required, the antibiotics neomycin or chloramphenicol were added to the growth media at concentrations of 50 and $10 \mu \mathrm{g} / \mathrm{ml}$, respectively.

Construction of the plasmid pK2-22. The complete coding region of egfp flanked by $S c a$ I restriction sites was amplified using the primers EGFP-fwd (CGAAAAGTACTACCATGGT GAGCAAGGGCGAGGAGCTGTTC) and EGFP-rev (GCAAA AGTACTACAGCCAAGCTTACTTGTACAGC) and pTST101 as template. pTST101 contains a fusion of malE (encoding a maltose-binding protein) and egfp, which encodes the EGFP (31). The 755-bp polymerase chain reaction (PCR) product was cloned into pGEM-T Easy vector (Promega Corp., Madison, WI) to generate the plasmid pGemEGFP. A DNA fragment of 739-bp ScaI carrying the egfp gene from the latter plasmid was inserted into the $C$. michiganensis subsp. michiganensis shuttle vector pDM302 (25) by replacing the chloramphenicol resistance cassette (the 941-bp ScaI fragment). Afterward, the ScaI site in the 3' untranslated region of $e g f p$ was deleted by substitution of the 696 HindIII fragment with a HindIII-digested PCR fragment amplified with primers H1: GTAAGCTTGGCTGTAGTGCTC and H2: GTGAAGCTTATCGATCGAGC (plasmid pGemEGFP_H). Finally, a ribosomal-binding site was introduced by cloning annealed oligonucleotides OSpeA CTAGTCAGTACTGATGC ATCAGGCCTCAGGAGG and OSpeB CCTCCTGAGGCCTGA TGCATCAGTACTGA (ribosomal-binding site is underlined) into SpeI/ScaI-digested pGemEGFP_H. Transformation of Escherichia coli and $C$. michiganensis subsp. michiganensis with this plasmid (pDM302EGFP-RBS) resulted in nonfluorescent colonies. Hence, $R s a \mathrm{I}$ fragments of the C. michiganensis subsp. michiganensis bacteriophage CMP1 (10,34) (GenBank accession number Gq241246) were cloned into the $S t u \mathrm{I}$ site $5 \mathrm{bp}$ upstream of the ribosomal-binding site to find an appropriate promoter-region for expression of egfp in $C$. michiganensis subsp. michiganensis. Transformation of E. coli with plasmid pK2-22 (Fig. 1), which carries a partially digested 254-bp RsaI DNA fragment of CMP1 (base pair position 50,302 to 50,048 in the CMP1 genome) led to a green fluorescent phenotype. pK2-22 was transferred into the wild-type strain $\mathrm{Cmm} 382$ and its derivatives as described by Stork et al. (29). Briefly, DNA of plasmid pK2-22 was extracted from E. coli JM109 and subsequently electroporated into Cmm382, 
Cmm27, and Cmm100, respectively. Recombinant bacteria were selected on SB agar plates (1\% tryptone, $0.5 \%$ yeast extract, $9.1 \%$ sorbitol, $34 \mathrm{mM} \mathrm{NaCl}, 20 \mathrm{mM} \mathrm{MgCl} 2,20 \mathrm{mM} \mathrm{CaCl}_{2}$, and agar at $15 \mathrm{~g} /$ liter) containing neomycin $(50 \mu \mathrm{g} / \mathrm{ml})$ after 7 days of incubation at $28^{\circ} \mathrm{C}$. Twenty neomycin-resistant colonies were randomly collected and screened for fluorescence emission by a fluorescence-read microplate reader. Although all transformants displayed fluorescence, they varied in their signal intensity; therefore, clones displaying fluorescence signals above 18,000 fluorescence units (FUs) were selected for further analysis.

Plant inoculation and colonization test. Seedlings of tomato (Solanum lycopersicum) cv1125 (Hishtil Ltd., Moshav Nehalim, Israel) were grown in nethouse conditions. Three-week-old tomato plants were stem punctured with a needle at the junction of the first two leaves and $10 \mu \mathrm{l}$ of bacterial suspension of $10^{8}$ cells $/ \mathrm{ml}$ was placed at the wound. Bacterial inoculum was prepared from cultures of $\mathrm{Cmm} 382$ or its derivatives after growth of $48 \mathrm{~h}$ in LB broth. At various time points $(0,3,7,15$, and 21 days after infection), $1 \mathrm{~cm}$ of stem was cut at different distances above and below the inoculation site and macerated in $1 \mathrm{ml}$ of distilled water, and serial 10-fold dilutions were plated on CNS plates. The numbers of CFU per gram of stem were determined and the mean of three plants was calculated. The experiments were repeated three times.

Fluorescence measurement. Fluorescence emission of C. michiganensis subsp. michiganensis strains harboring plasmid $\mathrm{pK} 2-22$ was measured from cultures grown for $48 \mathrm{~h}$ in LB broth amended with neomycin. Aliquots of $100 \mu \mathrm{l}$ of each culture suspension (optical density at $595 \mathrm{~nm}\left[\mathrm{OD}_{595}\right]=0.5$ ) were added to the wells of a black microtiter plate which was then read in a fluorescence microplate reader (Synergy 2 Multi-Mode Microplate Reader; Bio-Tek, Winooski, VT) using an excitation of 485 and emission at $528 \mathrm{~nm}$. FUs of each well were normalized by subtracting the background fluorescence value of control wells containing LB broth.

Stability of pK2-22 in Cmm382 and mutant derivatives. Stability of plasmid pK2-22 in vitro was determined with EGFPlabeled Cmm382, Cmm100, and Cmm27 grown on CNS agar plates without antibiotic at $28^{\circ} \mathrm{C}$ for $48 \mathrm{~h}$. Cells were harvested from the plates and diluted to $\mathrm{OD}_{595}=0.5$, and aliquots of $100 \mu \mathrm{l}$ were plated on fresh CNS plates. Successive transfers at 2-day intervals were repeated eight times. One hundred colonies were randomly collected and streaked on CNS agar plates containing neomycin. Colonies resistant to neomycin were further examined for fluorescence intensity as described above.

Stability assay of plasmid pK2-22 in strains grown in tomato plants was essentially carried out as described above for plant colonization. At various time points $(0,3,7,15$, and 30 days), stem samples of three plants, inoculated with EGFP-labeled Cmm382, were removed $2 \mathrm{~cm}$ above the inoculation site and macerated with sterile water, and serial 10 -fold dilutions were plated on CNS plates with or without neomycin. The CFU per gram of stem was determined and the mean of three independent experiments was calculated. At each time point, 20 single colonies were recovered from plates without antibiotic and diluted in phosphate buffer to $\mathrm{OD}_{595}=0.5$. The fluorescence of each colony was determined and the percentage of EGFP-expressing colonies, with fluorescence $>18,000$ FUs, was calculated.

CLSM. For in vivo examination, stems of tomato plants were inoculated with EGFP-labeled Cmm382, Cmm27, and Cmm100 as previously described. At each time point (3, 7, 15, and 30 days), plant tissues were collected from different sites above the inoculation site or from the apical region. The plant samples were transversally or longitudinally sectioned. At least 150 images taken from 50 plants were examined with a confocal laser-scanning microscope (model CLSM FluoView 500a; Olympus, Tokyo).

For in vitro studies, EGFP-labeled $C$. michiganensis subsp. michiganensis strains were grown in $3 \mathrm{ml}$ of LB broth for $48 \mathrm{~h}$ at $28^{\circ} \mathrm{C}$. Bacterial cultures were centrifuged and the pellet was washed once with sterile water and resuspended in the original volume of pure xylem sap (XS). XS for growth of $C$. michiganensis subsp. michiganensis was collected as follows. Stems of 14-week-old tomato plants were cut $10 \mathrm{~cm}$ above the ground. The stems were then placed horizontally to facilitate dripping of the sap into a $50-\mathrm{ml}$ sterile tube for a 2 -h period. The collected sap (from five plants) was filtered through a $0.22-\mu \mathrm{m}$ membrane filter (Minisart; Sartorius Stedim Biotech, Aubagne, France) prior to use as a pure growth medium. The cell suspension $(200 \mu \mathrm{l}$ of $\left.10^{10} \mathrm{cells} / \mathrm{ml}\right)$ in XS was placed on the polystyrene cover of 24-well plates and incubated at $28^{\circ} \mathrm{C}$ inside hermetic bags to avoid evaporation for 4 days followed by examination with CLSM.

Scanning electron microscopy. Tomato plants were stem inoculated as described above. Stems were collected at 3 and 15 days postinoculation (dpi) and longitudinally cut. The sections were fixed in $2.5 \%$ glutaraldehyde in sterile phosphate-buffered saline. After washing, the tissue samples were dehydrated by successive ethanol treatment. Solvents were removed by critical point drying. The samples were mounted on aluminum stubs and sputter-coated (E5100, Polaron; Quorum Technologies Ltd., West Sussex, UK) with gold. Images were captured with a scanning electron microscope (JSM 840A; Jeol Ltd., Tokyo) using a Scandium scanning electron microscope imaging platform (Olympus).

Crystal violet assay for bacterial attachment. The assay for bacterial attachment was carried out following the procedure described by Davey and O'Toole (7). Culture of Cmm382 was grown in LB broth for $49 \mathrm{~h}$ at $28^{\circ} \mathrm{C}$ and then transferred to the same medium at 1:1000 dilution. After reaching an $\mathrm{OD}_{595}=0.5$, the bacterial suspension was centrifuged and the pellet was washed once and resuspended in $3 \mathrm{ml}$ of sterile water. The suspension $(50 \mu \mathrm{l})$ was added to individual wells of 24 -well multidishes containing $150 \mu \mathrm{l}$ of XS, M9, or LB medium. The multidishes were incubated for $72 \mathrm{~h}$ at $28^{\circ} \mathrm{C}$ without agitation. After incubation, the culture was gently removed using a pipette, and wells were washed twice with $150 \mu \mathrm{l}$ of sterile water. Following fixation at $60^{\circ} \mathrm{C}$ for $20 \mathrm{~min}$, surface-attached bacteria were stained with $0.1 \%$ crystal violet solution for $1 \mathrm{~h}$ at room temperature. The multidishes were then washed gently three times with $150 \mu \mathrm{l}$ of sterile water and air dried for $1 \mathrm{~h}$ for visual qualitative analysis. For quantitative analysis, crystal violet in each well was solubilized by adding $100 \mu \mathrm{l}$ of $95 \%$ ethanol and absorption of the solution was then measured at $595 \mathrm{~nm}$ using a microtiter plate reader.

Statistical analysis. Statistical analyses were performed using the Excel software (Microsoft, Seattle) and JMP V7 (SAS Institute, Cary, NC).

\section{RESULTS}

Generation of EGFP-labeled $C$. michiganensis subsp. michiganensis. To generate a GFP-tagged C. michiganensis subsp. michiganensis, the EGFP was chosen because this protein was successfully used as reporter in related actinomycete Streptomyces coelicolor and for visualization of an endophytic Streptomyces sp. (5). The altered codon usage of the gene corresponds more closely to that of high GC organisms $(5,32)$ and exhibits a stronger fluorescence compared with the wild-type GFP. The egfp was amplified from the expression plasmid pTST101 (31) and cloned into the $C$. michiganensis subsp. michiganensis shuttle vector pDM302, which confers neomycin resistance (24). An artificial ribosomal-binding site (GGAGG) was inserted 7 bp upstream of the start codon. Because this construct showed no fluorescence, both in E. coli and in C. michiganensis subsp. michiganensis, the $C$. michiganensis subsp. michiganensis bacteriophage CMP1 $(10,34)$ was employed for isolation of a random 254-bp RsaI DNA-fragment to serve as a promoter (Fig. 1). 
Transfer of the resulting plasmid, designated as $\mathrm{pK} 2-22$, into the wild-type strain $C m m 382$ and its derivatives, as well as into $E$. coli, resulted in fluorescent clones. Twenty neomycin-resistant colonies were randomly collected and screened for fluorescence emission by a fluorescence-read microplate reader. Although all transformants displayed fluorescence, they varied in their signal intensity. Five colonies that displayed fluorescence above 18,000 FUs were selected for further analysis.

Characterization of the EGFP-labeled $C$. michiganensis subsp. michiganensis. EGFP-labeled Cmm382, Cmm100, and Cmm27 showed a growth rate similar to that of the wild-type strain when grown in liquid $\mathrm{LB}$ at $28^{\circ} \mathrm{C}$, indicating that the presence of pK2-22 or expression of egfp did not impair growth in vitro (data not shown). Stability of pK2-22 in Cmm382, $\mathrm{Cmm} 100$, and $\mathrm{Cmm} 27$ was evaluated after eight successive transfers of 2-day intervals on selective media (CNS) plates without neomycin. One hundred randomly selected colonies showed resistance to neomycin and displayed fluorescence intensity similar to that of the EGFP-labeled parent strain $(P<0.05)$. Plasmid stability was also evaluated in tomato plants by monitoring the population of EGFP-labeled $C \mathrm{~mm} 382$ in stem tissue for a period of 30 days (Table 1). Tissue samples taken from $2 \mathrm{~cm}$ above the inoculation site exhibited a similar number of colonies when cultured on CNS plates with or without neomycin, indicating that the plasmid was stable in Cmm382-infected tomato plants. The lower number of colonies that were recovered after 30 dpi (Table 1) could result from bacterial cell death during advanced stages of infection. However, no significant differences in colony number recovered on plates with or without neomycin were observed, indicating stability of the plasmid. EGFP expression by $\mathrm{Cmm} 382$ in planta was examined by monitoring the fluorescence of 20 colonies grown on CNS without neomycin. An EGFP signal $>18,000$ FUs was detected in all of the monitored colonies at 3, 7, and 15 dpi (Table 1) whereas, at $30 \mathrm{dpi}$, only $70 \%$ of the colonies were fluorescent. The latter result suggests that the level of EGFP expression and resistance to neomycin are not entirely correlated. It could result from a loss of plasmid copies under nonselective conditions or attenuation of the GFP expression.

Wilt symptoms of tomato plants inoculated with EGFP-labeled Cmm382 or the wild-type Cmm382 appeared after 12 days (Supplemental Figure 1), suggesting that virulence was not impaired by the presence of the EGFP-expressing plasmid.

Colonization patterns of EGFP-labeled $\mathrm{Cmm382}$ during tomato infection. The ability of EGFP-labeled Cmm382 to colonize tomato plants during infection was examined by CLSM. Longitudinal section images of the tomato stem taken at 3 dpi showed extensive multiplication and aggregates of C. michiganensis subsp. michiganensis that filled the lumen of xylem

TABLE 1. Stability of pK2-22 in strain Clavibacter michiganensis subsp. michiganensis NCPPB382 (Cmm382) in tomato plant

\begin{tabular}{lrrr}
\hline & \multicolumn{2}{c}{$\log (\mathrm{CFU} / \mathrm{g} \text { of tissue })^{\mathrm{a}}$} & \\
\cline { 2 - 3 } Days & \multicolumn{1}{c}{ Neo+ } & Neo- & egfp-expressing colonies $(\%)^{\mathrm{b}}$ \\
\hline 0 & $5.5 \pm 0.2$ & $5.8 \pm 0.2$ & $100 \pm 0$ \\
3 & $10.1 \pm 0.2$ & $10.0 \pm 0.1$ & $100 \pm 0$ \\
7 & $10.2 \pm 0.2$ & $10.4 \pm 0.4$ & $100 \pm 0$ \\
15 & $9.4 \pm 0.9$ & $9.8 \pm 1.0$ & $100 \pm 0$ \\
30 & $4.6 \pm 0.9$ & $5.3 \pm 0.8$ & $70 \pm 8$ \\
\hline
\end{tabular}

a Stems of 3-week-old tomato plants were inoculated with $10 \mu$ of suspension $\left(10^{8}\right.$ cells $/ \mathrm{ml}$ ) of enhanced green fluorescent protein (EGFP)-labeled Cmm382. Tissue samples at different days postinoculation were taken from $2 \mathrm{~cm}$ above the inoculation site and plated on CNS agar plates with (Neo+) or without (Neo-) neomycin.

b Fluorescence of 20 single colonies, collected from nonselective plates, was measured at each time point, and the percentage was calculated from the number of colonies with fluorescence above 18,000 fluorescence units. Results represent the means and standard deviation $( \pm)$ of three independent experiments. vessels (Fig. 2A). Images taken at $7 \mathrm{dpi}$ showed that $C$. michiganensis subsp. michiganensis cells adhered to the spiral secondary wall thickening of protoxylem, although an abundance of aggregated cells could still be observed within the lumen of the vessels (Fig. 2B). The specific and strong affinity of C. michiganensis subsp. michiganensis to the spiral secondary wall thickening was also evident when spiral elements were separated from damaged protoxylem vessels in images taken at $15 \mathrm{dpi}$ (Fig. 2C). It is noteworthy that a screen of 150 images revealed that $C$. michiganensis subsp. michiganensis preferentially colonized the protoxylem and was not detected in adjacent metaxylem vessels (Fig. 2B), suggesting that horizontal passage of cells does not or rarely occurs at this stage. However, in damaged tissue, at later stages of infection and symptom production (e.g., $30 \mathrm{dpi}$ ), $C$. michiganensis subsp. michiganensis cells were dispersed from the vessels into adjacent parenchymal cells (Fig. 2D). Transversal sections of tomato stems revealed biofilm-like structures composed of large aggregates of bacterial cells which appeared attached to the xylem wall (Fig. 2E). Highly colonized tracheary elements were also observed in transversal mesophyll-sections in a wilted leaf taken from the apical region (Fig. 2F). The EGFPlabeled mutants $C m m 27$ and $C m m 100$ were examined by CLSM after 7 dpi and showed dispersed bacterial cells compared with the massive colonization and aggregate formation of the wild-type strain (Supplemental Figure 2).

Longitudinal sections of tomato stems inoculated with $C$. michiganensis subsp. michiganensis taken at $3 \mathrm{~cm}$ above the inoculation site were also examined by scanning electron microscopy (SEM). C. michiganensis subsp. michiganensis cells were attached to the xylem wall and developed aggregates among the spiral elements at 3 dpi (Fig. 3A). At $15 \mathrm{dpi}$, C. michiganensis subsp. michiganensis cells densely covered the spiral rings of xylem vessels (Fig. 3B). Furthermore, close-up images of infected xylem sections sampled at 15 dpi showed the presence of $C$. michiganensis subsp. michiganensis cells on perforated cell wall remnants (Fig. 3C), whereas continuous secondary wall thickening was generally observed in noninoculated xylem vessels (Fig. 3D).

Movement of $C$. michiganensis subsp. michiganensis in tomato. Movement of $C$. michiganensis subsp. michiganensis in the xylem vessels is crucial for tomato systemic infection (15). Confocal images of tomato plants infected with EGFP-expressing Cmm382 showed that the pathogen colonized the whole plant and reached the apex within 15 dpi (Fig. 2C, D, and F). However, screening of 50 confocal images of tomato plants infected by EGFP-labeled Cmm100 (lacking pCM1 and pCM2) and Cmm27 (lacking the $\operatorname{chp} /$ tom $A$ region) did not reveal the presence of the mutant strains in the apical parts of the stem. Therefore, it was of interest to examine further whether the inability of the nonpathogenic strains $C m m 100$ and $C m m 27$ to induce symptoms in tomato correlates to lower colonization and delayed spread within the plant. Stems of 3-week-old tomato plants were puncture inoculated with suspensions of Cmm382, Cmm27, and Cmm100, and the bacterial colonization at different locations above the inoculation site up to the apical region was monitored after 3, 7, 15, and $21 \mathrm{dpi}$ (Fig. 4). At $3 \mathrm{dpi}$, all the examined strains showed similar bacterial titers of approximately $10^{9} \mathrm{CFU} / \mathrm{g}$ at the inoculation site. However, whereas Cmm382 could colonize the first $4 \mathrm{~cm}, \mathrm{Cmm} 27$ and $C m m 100$ were only detected at the $2-\mathrm{cm}$ distance. At $7 \mathrm{dpi}, \mathrm{Cmm} 382$ reached the 6-cm site with a titer of $10^{6} \mathrm{CFU} / \mathrm{g}$ whereas $\mathrm{Cmm} 27$ and $\mathrm{Cmm} 100$ could be isolated only from the initial $4 \mathrm{~cm}$ with a lower titer of $10^{5}$ and $10^{3} \mathrm{CFU} / \mathrm{g}$, respectively. At $15 \mathrm{dpi}$, when disease symptoms appeared in stems and leaves of the wild-type inoculated plants, the pathogen could be isolated from the apical region $(30 \mathrm{~cm})$ of the plant with a titer of $10^{9} \mathrm{CFU} / \mathrm{g}$. In contrast, $\mathrm{Cmm} 27$ and $\mathrm{Cmm} 100$ were not detected beyond $4 \mathrm{~cm}$ above the inoculation site (Fig. 4). At $21 \mathrm{dpi}, \mathrm{Cmm} 382$ reached a high population level of $10^{10} \mathrm{CFU} / \mathrm{g}$ at 
the apex of the plant (40 $\mathrm{cm}$ above the infection site) whereas $\mathrm{Cmm} 27$ and $\mathrm{Cmm} 100$ remained confined to a $6-\mathrm{cm}$ region above the inoculation site with a significantly lower titer of $10^{3}$ and $2 \times$ $10^{2} \mathrm{CFU} / \mathrm{g}$, respectively. The low titer $\left(10^{5} \mathrm{CFU} / \mathrm{g}\right)$ of $\mathrm{Cmm} 382$ $21 \mathrm{dpi}$ in the first $2 \mathrm{~cm}$ could be assigned to cell death due to canker development in this area. The possibility that passive movement is involved in the migration of the mutants for short distances cannot be excluded.

The basipetal movement of Cmm382, Cmm27, and Cmm100 was also monitored (Fig. 5). Results indicate that only Cmm382 could reach $10^{3}$ and $10^{7} \mathrm{CFU} / \mathrm{g}$ at $4 \mathrm{~cm}$ below the inoculation site after 3 and 7 days, respectively. Only after 15 and 21 dpi did $\mathrm{Cmm} 27$ and $\mathrm{Cmm} 100$ also colonize the $4-\mathrm{cm}$ site but with a titer of approximately four orders of magnitude lower compared with the wild-type strain.

The foregoing results support the possibility that genes located on the pCM1 and pCM2 plasmids and the chp/tomA PAI might play a significant role in effective acropetal and basipetal movement as measured by colonization of the pathogen during systemic infection of tomato. To further examine this premise, acropetal movement of Cmm100, Cmm101 (lacking pCM2), Cmm102 (lacking pCM1), Cmm27, Cmmchp $C^{-}$(a mutant in $c h p C$ ), and $C m m 382$ were compared (Fig. 6). CmmchpC $C^{-}$was selected for this experiment because $\operatorname{ch} p C$ has been previously implicated in virulence (29). Bacterial titers were measured in the apical region at 15 dpi as described earlier. Results showed that Cmm101, Cmm102, and CmmchpC $C^{-}$colonized the apical region $(20 \mathrm{~cm})$ but with a titer 0.9 to 3.7 orders of magnitude lower compared with the wild-type strain, whereas Cmm100 and Cmm27 were not detected (Fig. 6). These findings suggest that genes located on either pCM1 or pCM2 contribute to colonization in the apex.
Effect of XS on attachment and aggregate formation by $C$. michiganensis subsp. michiganensis. The possibility that substances present in the XS might cause $C$. michiganensis subsp. michiganensis to incite attachment, aggregation, and biofilm formation was examined by employing an in vitro assay for biofilm detection in which the effect of XS, LB, and minimal M9 media were compared. Cmm382 grown in XS developed an apparent biofilm that consisted of large aggregate of adherent cells (Fig. 7A). In contrast, cells grown in minimal M9 medium formed a very weak biofilm with no signs of aggregation and those grown in LB showed only few aggregates distributed over the polystyrene well surface (Fig. 7A). Spectrophotometric determination $\left(\mathrm{OD}_{590}\right)$ of the adherent cells assayed by crystal violet staining also showed that biofilm formation in XS was $2.6 \mathrm{com}-$ pared with 0.9 and 0.2 in minimal M9 and LB media, respectively.

Confocal microscopy was performed to examine aggregate formation of $C$. michiganensis subsp. michiganensis grown in XS. Suspension of EGFP-labeled Cmm382, Cmm27, and Cmm100 were grown in fresh XS. After 4 days, cells of Cmm382 readily formed large aggregates on a polystyrene surface whereas $\mathrm{Cmm} 27$ cells did not form aggregates (Fig. 7B). Cmm100 showed a significant decrease in aggregation compared with $\mathrm{Cmm} 382$ but small aggregates were still observed (Fig. 7B).

\section{DISCUSSION}

GFP-tagged cells provide a most useful tool to monitor bacterial pathogens during disease development (22). The powerful advantage of GFP labeling is that the localization of individual cells or clusters of bacterial cells can be studied over a long
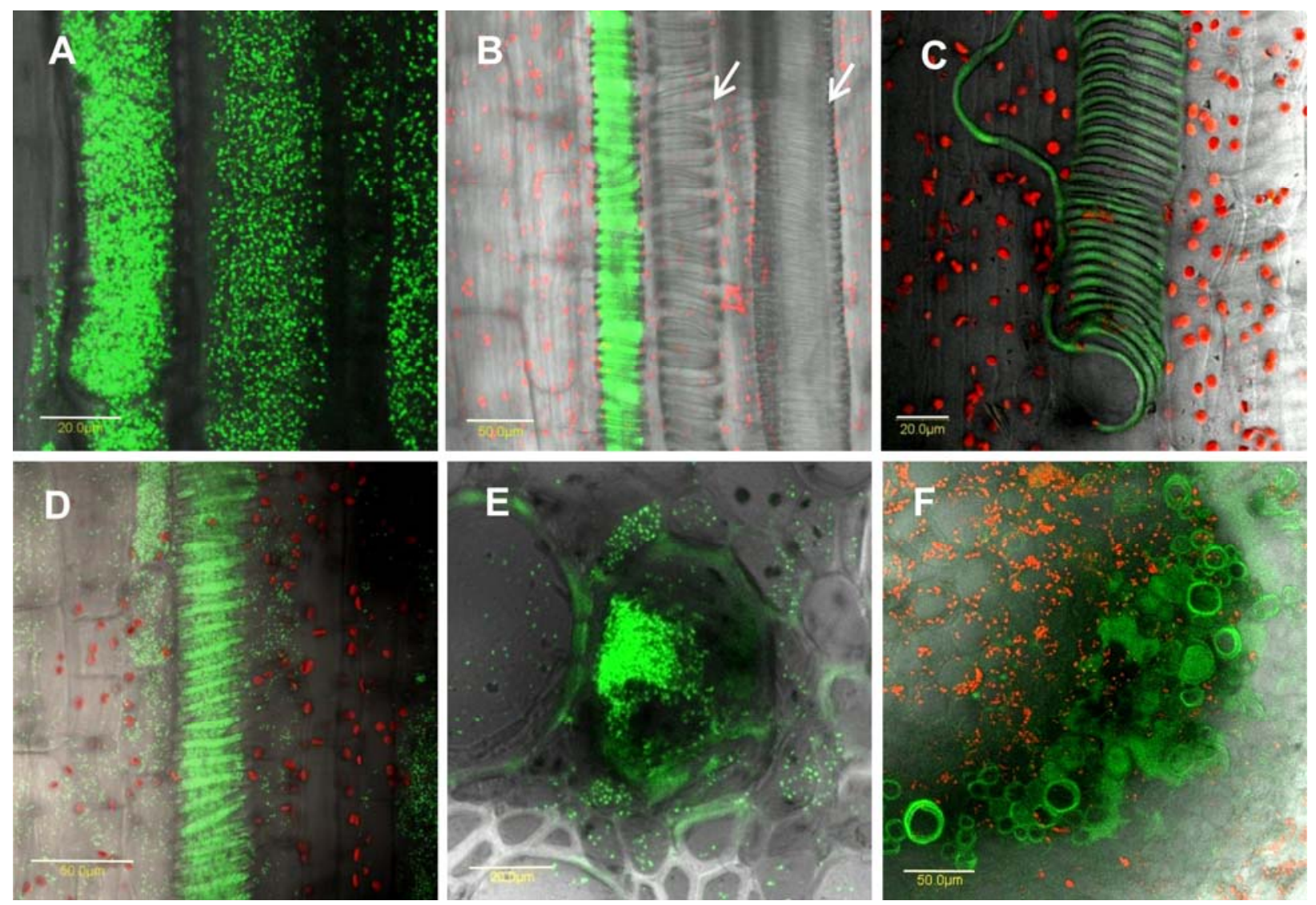

Fig. 2. Colonization of tomato plants by enhanced green fluorescent protein (EGFP)-labeled Clavibacter michiganensis subsp. michiganensis. Tomato seedlings were puncture inoculated with a bacterial suspension at the junction of the first two leaves and localization of EGFP-labeled strain $C$. michiganensis subsp. michiganensis NCPPB382 was examined by confocal laser scanning microscopy at $\mathbf{A}, 3 ; \mathbf{B}, 7 ; \mathbf{C}, 15 ; \mathbf{D}, 30 ; \mathbf{E}, 7 ;$ and $\mathbf{F}, 15$ days postinoculation. Images were taken from longitudinally (A to D) and transversally cut (E) tomato stems and a wilted leaf (F). Images were captured at $3 \mathrm{~cm}$ above the inoculation site (A, B, and E) and at the apical region (C, D, and F). White arrows indicate noncolonized vessels. Red dots are plastids. Scale bars: $20 \mu \mathrm{m}$ in A, C, and E; $50 \mu \mathrm{m}$ in B, D, and F. 
period of time in living tissues and even after cell death. Although the GFP reporter has been commonly used to determine movement and localization of many plant-associated bacteria (6), this is the first report in which GFP has been stably expressed in $C$. michiganensis subsp. michiganensis and applied for studying bacterial wilt and canker of tomato.

The interaction of $C$. michiganensis subsp. michiganensis with tomato has been divided into two phases, an endophytic stage and a symptom-inducing stage (15). The transition into the second stage relied on extensive multiplication of the pathogen in the xylem to reach a high population that is clearly reflected by the dense bacterial cells and aggregates filling the vessel lumen (Fig. $2 \mathrm{~A}$ and $\mathrm{B}$ ). A cluster of C. michiganensis subsp. michiganensis cells forming a biofilm-like structure was revealed in a cross section of the xylem vessels in stems (Fig. 2E) and, together with bacterial aggregates observed by SEM (Fig. 3), it can be concluded that $C$. michiganensis subsp. michiganensis produces biofilm-like structures in planta similar to other vascular bacterial pathogens (6). It is reasonable to expect that the severity of the disease caused by $C$. michiganensis subsp. michiganensis would increase with a larger proportion of vessels that become heavily colonized leading to a progressively lower water conduction capability.

A most striking phenomenon is the specific and firm adherence of $C$. michiganensis subsp. michiganensis to the spiral secondary wall thickening of xylem vessels (Fig. 2B to D). The bacterial surface adhesion to the spiral thickening was maintained even in isolated spirals resulting from vessel deterioration (Fig. 2C). Damaged vessels in advanced stages of infection also facilitated the migration of $C$. michiganensis subsp. michiganensis into adjacent parenchymal cells (Fig. 2D). The preferential adhesion of $C$. michiganensis subsp. michiganensis to the secondary wall thickening is not understood. Occurrence of specific adherence to annular secondary cell wall thickening was reported for the gramnegative $P$. stewartii subsp. stewartii (23). Bacterial surfaceassociated structures, including polysaccharides and proteinaceous pili or fimbriae, are often involved in attachment to inert surfaces, to plants as well as to other bacterial cells and biofilm formations (6). EPS was implicated in biofilm formation and virulence of gram-negative vascular pathogens such as $P$. stewartii subsp. stewartii, X. fastidiosa, or Erwinia amylovora $(6,21,33)$. EPS could create a physical barrier between the bacterial adhesion factors and a given substrate (23). Although EPS is produced by $C$. michiganensis subsp. michiganensis (12), its significance in $C$. michiganensis subsp. michiganensis virulence was ruled out because mutants containing reduced amounts of EPS or changed sugar composition were not affected in symptom development or colonization (3). However, the possibility that specific adhesion of $C$. michiganensis subsp. michiganensis to the spiral thickening of the xylem vessels might be mediated by adhesins such as fimbriae or pili cannot be excluded.

A clear preference for colonization of protoxylem as opposed to the metaxylem vessels was established for $C$. michiganensis subsp. michiganensis. The metaxylem vessels were generally ob-
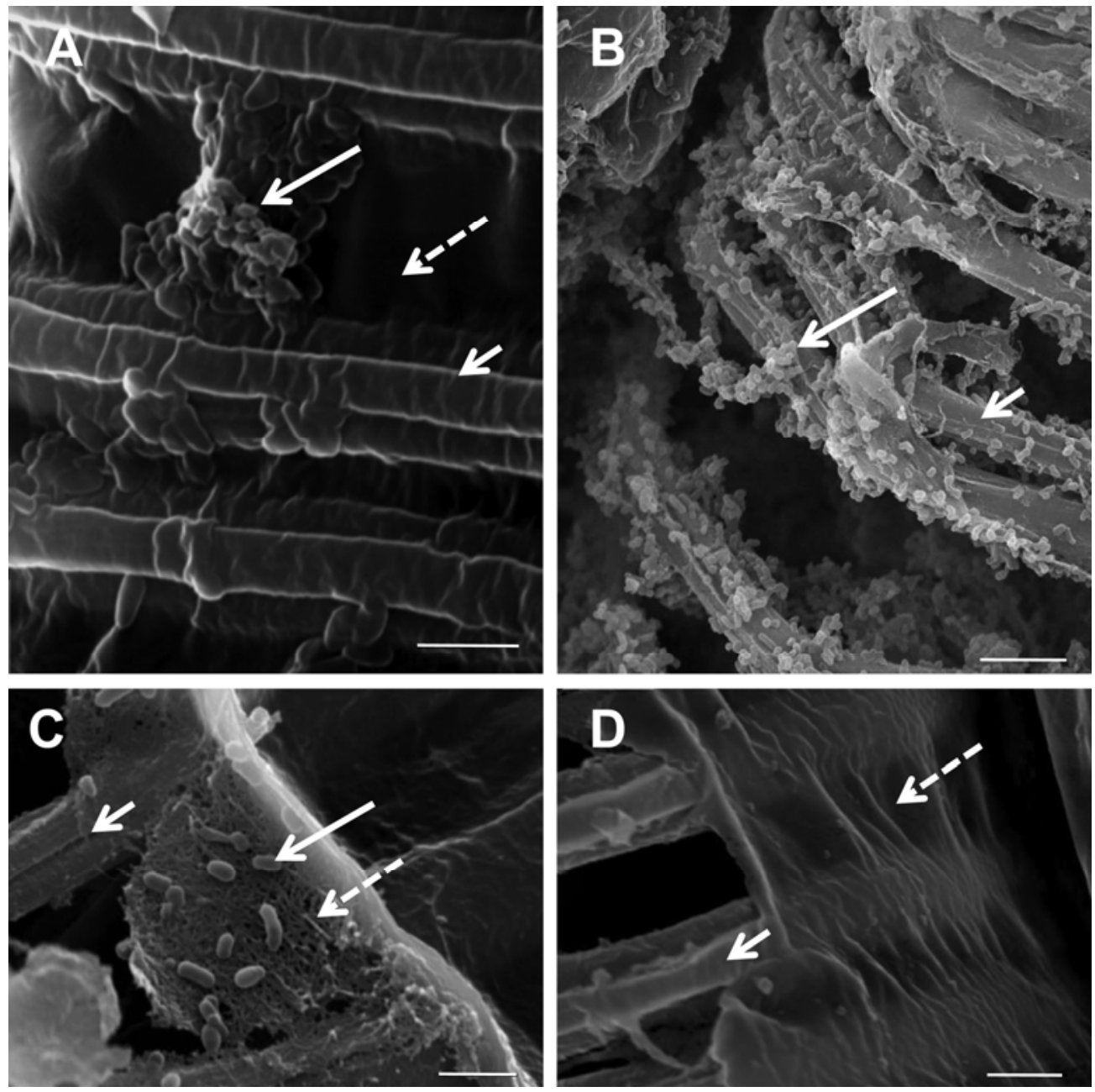

Fig. 3. Visualization of Clavibacter michiganensis subsp. michiganensis in tomato plants by scanning electron microscopy. Longitudinal sections of xylem vessels taken $3 \mathrm{~cm}$ above the inoculation site at $\mathbf{A}, 3$ and $\mathbf{B}$ and $\mathbf{C}, 15$ days postinoculation following inoculation with suspensions of strain $C$. michiganensis subsp. michiganensis NCPPB382 or D, mock inoculation. Solid, dashed, and short arrows indicate bacterial cells, xylem wall, and spiral secondary wall thickening, respectively. Scale bars: $2 \mu \mathrm{m}$ in A, C, and D; $5 \mu \mathrm{m}$ in B. Images are representative of at least 25 sections for each time point. 

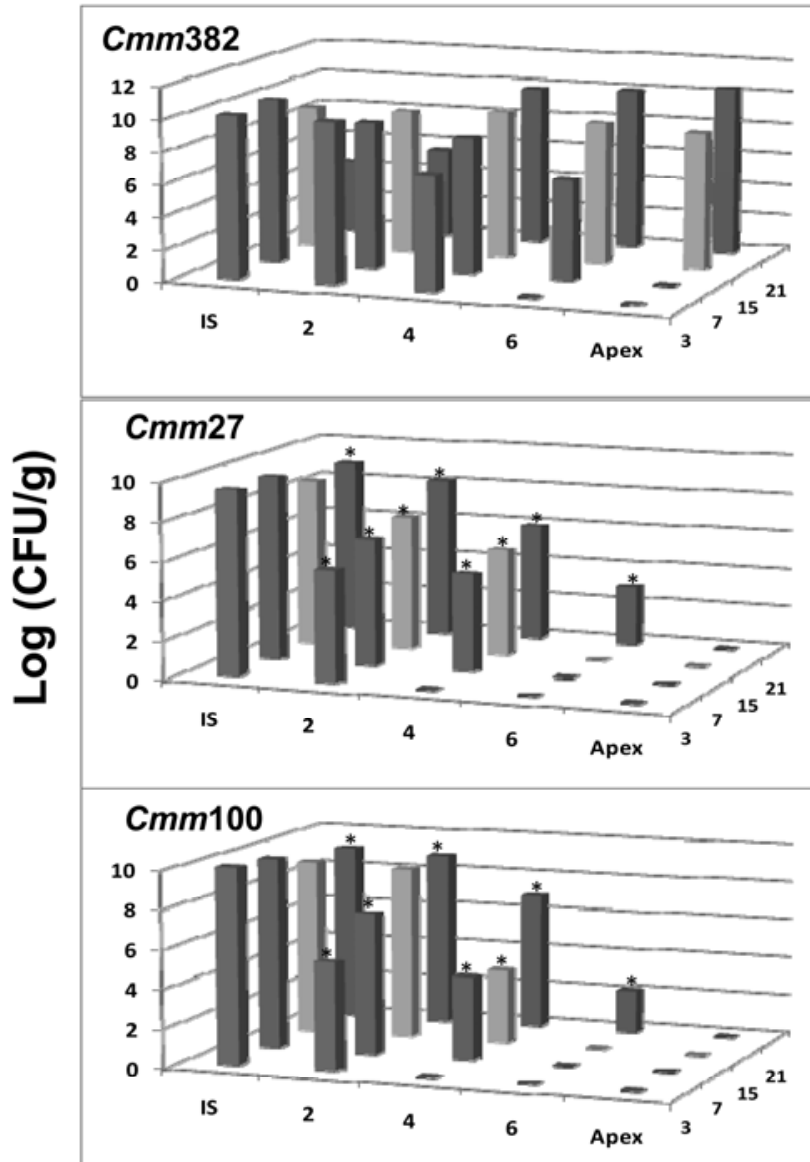

Distance from inoculation site $(\mathrm{cm})$

Fig. 4. Colonization of tomato plants by Clavibacter michiganensis subsp. michiganensis strains NCPPB382 (Cmm382), Cmm27, and Cmm100 at different times and distance from the inoculation site. Stems of 3-week-old tomato plants were puncture inoculated with suspensions of $\mathrm{Cmm} 382$, $\mathrm{Cmm} 27$, and $\mathrm{Cmm} 100$. Stem segments $(1 \mathrm{~cm})$ were individually collected and homogenized with $1 \mathrm{ml}$ of distilled water, and serial dilutions were plated on CNS medium. Tomato apex segments were taken at distances of approximately $12,15,30$, and $40 \mathrm{~cm}$ from the inoculation site (IS) after 3, 7, 15, and 21 days, respectively. Results represent the means of three independent experiments. Asterisks denote significant differences $(P<0.05)$ in $\mathrm{Cmm} 27$ and Cmm100 compared with $C m m 382$ at each distance and time point according to Student's $t$ test.

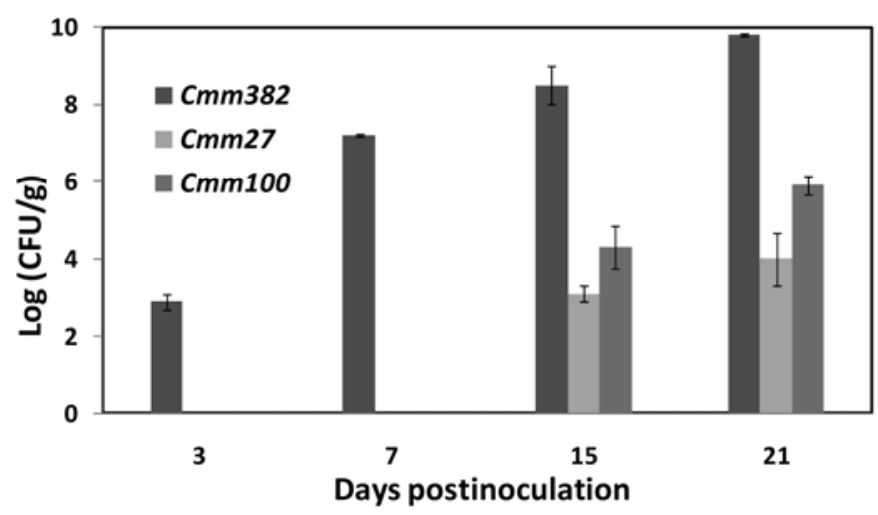

Fig. 5. Basipetal colonization of tomato plants by Clavibacter michiganensis subsp. michiganensis strains NCPPB382 (Cmm382), Cmm27, and Cmm100. Stem segments $(1 \mathrm{~cm})$ of tomato plants were collected at $4 \mathrm{~cm}$ below the inoculation site. Results represent the means of three independent experiments with standard deviations. Colonization of $\mathrm{Cmm} 27$ and $\mathrm{Cmm} 100$ was statistically different $(P<0.05)$ compared with $C m m 382$ after 15 and 21 days according to Student's $t$ test. Asterisks denote significant differences $(P<$ 0.05) in Cmm 27 and Cmm 100 compared with $\mathrm{Cmm} 382$. served to be free of bacteria even when located adjacent to heavily infected protoxylem vessels (Fig. 2B). This phenomenon is not understood. Additionally, transversal movement among vessels via bordered pits, as observed for $X$. fastidiosa (27), could not be detected. The protoxylem vessels differentiate in the primary plant body that have not completed their growth and differentiation, whereas the metaxylem matures largely after elongation is completed (13). Therefore, it might be postulated that $C$. michiganensis subsp. michiganensis migrates through the apoplast and invades the protoxylem but not the metaxylem during early development of the vessels. The observation that many vessels are not infected might explain the unilateral wilting observed with $C$. michiganensis subsp. michiganensis, as is also

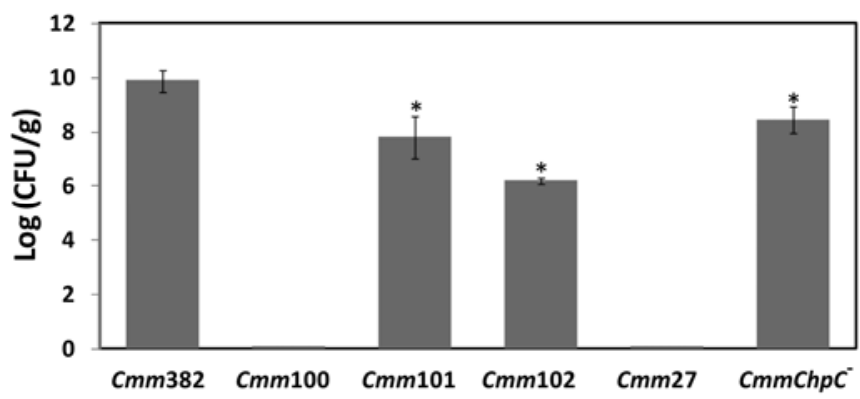

Fig. 6. Colonization of tomato apex by Clavibacter michiganensis subsp. michiganensis strains NCPPB382 (Cmm382), Cmm100, Cmm101, Cmm102, $\mathrm{Cmm27}$, and $\mathrm{CmmchpC}$. Stems of 3-week-old tomato plants were puncture inoculated with suspensions of the wild-type Cmm382, Cmm100 (lacking pCM1 and pCM2), Cmm101 (lacking pCM2), Cmm102 (lacking pCM1), and $C m m c h p C^{-}$(a mutant of $\operatorname{chpC}$ ). Bacterial growth in the apex was measured at 15 days postinoculation. Results represent the means of three independent experiments with standard deviations. Asterisks denote significant differences $(P<0.05)$ in $C m m 101, C m m 102$, and $C m m c h p C^{-}$population compared with Cmm382 according to Student's $t$ test.

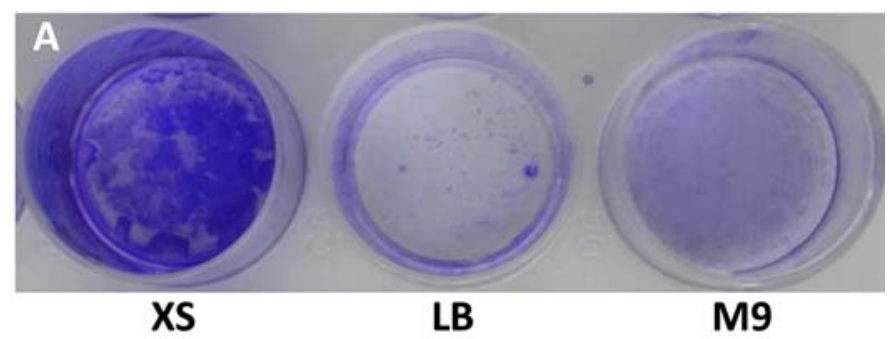

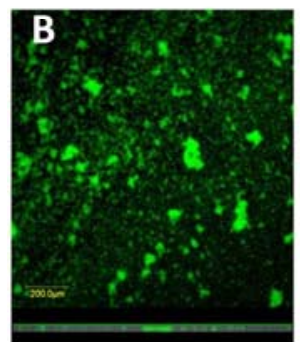

$\mathrm{Cmm} 382$

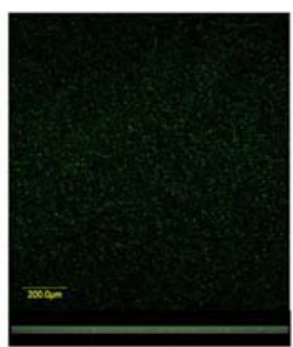

Cmm27

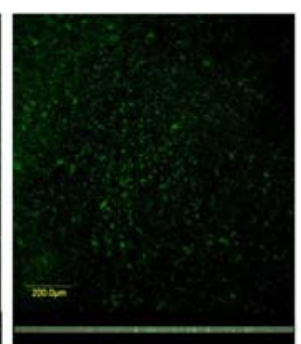

Cmm100
Fig. 7. Aggregation and biofilm formation by Clavibacter michiganensis subsp. michiganensis. A, Crystal violet staining assay with $C$. michiganensis subsp. michiganensis strain NCPPB382 (Cmm382) grown in different culture media. Cmm382 was grown in wells of microtiter plates in xylem sap (XS), minimal M9 (M9), and Luria-Bertani broth (LB) media and stained with crystal violet after 3 days as described in Materials and Methods. B, Enhanced green fluorescent protein (EGFP)-labeled Cmm382, Cmm27, and Cmm100 grown in xylem sap. EGFP-labeled $C$. michiganensis subsp. michiganensis $\left(10^{10}\right.$ cells $\left./ \mathrm{ml}\right)$ grown on polystyrene surfaces were visualized by confocal laser-scanning after 4 days. Images on the bottom are sagittal $(x z)$ planes. Scale bars, $200 \mu \mathrm{m}$. A minimum of five independent experiments was carried out for $\mathrm{A}$ and $\mathrm{B}$ with similar results. 
the case in other bacterial and fungal wilt diseases. This might be viewed as a strategy of the pathogen to keep the plant alive as a nutritional source.

C. michiganensis subsp. michiganensis can readily colonize tomato xylem in both acropetal and basipetal directions (Figs. 4 and 5). Translocation in both directions has been previously shown by a bioluminescent $C$. michiganensis subsp. michiganensis mutant in grafted tomato seedlings (35). The colonization pattern is largely dependent on expression of genes located on the chp/tomA PAI and the two pathogenicity plasmids, pCM1 and pCM2 (Fig. 4). In the presence of chp/tomA PAI but absence of either pCM1 or pCM2, C. michiganensis subsp. michiganensis could be detected in the apex region but with a significantly lower rate (Fig. 6). It might be hypothesized that conversion of $C$. michiganensis subsp. michiganensis from an endophyte into a pathogen was achieved by horizontal gene transfer of genes located primarily on mobilizable elements (i.e., the chp/tomA PAI and plasmids pCM1 and pCM2). The dominating genes on these elements are the multiple serine proteases of different families (14). Thus, pCM1 harbors one serine proteases of the Ppa family, pCM2 harbors three serine proteases of the Chp family, and the chp/tomA PAI contains members of three serine protease families (namely, Chp, Ppa, and subtilase). Most of these serine proteases were shown to be secreted into the XS during initial stages of infection (unpublished data). Results obtained can be best explained by the requirement of multiple serine proteases for $C$. michiganensis subsp. michiganensis colonization and movement in the plant. Thus, Cmm100 could not be detected in the apical region, whereas $C m m 101$ or $C m m 102$ could (Fig. 6). Similarly, Cmm27 did not move up to the apex whereas the mutant in $\operatorname{chpC}$ could (Fig. 6). Therefore, it might be postulated that a combination of serine proteases located on both the PAI and the plasmids are necessary for optimal movement and virulence. The observation that only $\mathrm{Cmm} 382$ formed aggregates in XS as opposed to $\mathrm{Cmm} 100$ and $\mathrm{Cmm} 27$ (Fig. 7B) also might support their involvement in biofilm formation. The presence of partial serine proteases was sufficient for endophytic multiplication of $C$. michiganensis subsp. michiganensis at the infection site (Fig. 4) but not for progressive colonization in remote locations. It could be postulated that serine proteases secreted by the pathogen fulfill two roles, presumably via signal transduction: (i) suppression of defenses and (ii) release of nutrients from surrounding xylem parenchymal cells to support the extensive bacterial growth and disease development.

\section{ACKNOWLEDGMENTS}

This work was supported by the DGF program for Trilateral Cooperation among Israel, the Palestinian Authority, and Germany (grant number EI 535/12-2) and the United States-Israel Binational Agricultural Research and Development Fund (grant number IS-4403-11C). We thank E. Blausov and Vered H. for their helpful assistance in CLSM and SEM.

\section{LITERATURE CITED}

1. Baccari, C., and Lindow, S. E. 2011. Assessment of the process of movement of Xylella fastidiosa with susceptible and resistant grape cultivars. Phytopathology 101:77-84

2. Balaji, V., Mayrose, M., Sherf, O., Jacob-Hirsh, J., Eichenlaub, R., Iraki, N., Manulis-Sasson, S., Rechavi, G., Barash, I., and Sessa, G. 2008. Tomato transcriptional changes in response to Clavibacter michiganensis subsp. michiganensis reveal a role for ethylene in disease development. Plant Physiol. 146:1797-1809.

3. Bermpohl, A., Dreier, J., Bahro, R., and Eichenlaub, R. 1996. Exopolysaccharides in the pathogenic interaction of Clavibacter michiganensis subsp. michiganensis with tomato plants. Microbiol. Res. 151:391-399.

4. Chalupowicz, L., Cohen-Kandli, M., Dror, O., Eichenlaub, R., Gartemann, K.-H., Sessa, G., Barash, I., and Manulis-Sasson, S. 2010. Sequential expression of bacterial virulence and plant defense genes during infection of tomato with Clavibacter michiganensis subsp. michiganensis. Phytopathology 100:252-261.
5. Coombs, J. T., and Franco, C. M. M. 2003. Visualization of an endophytic Streptomyces species in wheat seed. Appl. Environ. Microbiol. 69:42604262.

6. Danhorn, T., and Fuqua, C. 2007. Biofilm formation by plant-associated bacteria. Annu. Rev. Microbiol. 61:401-422.

7. Davey, M. E., and O'Toole, G. A. 2000. Microbial biofilms: From ecology to molecular genetics. Microbiol. Mol. Biol. Rev. 64:847-867.

8. Dow, J. M., Crossman, L., Findlay, K., He, Y. Q., Feng, J. X., and Tang, J. L. 2003. Biofilm dispersal in Xanthomonas campestris is controlled by cell-cell signaling and is required for full virulence to plants. Proc. Natl. Acad. Sci. USA 100:10995-11000.

9. Dreier, J. D., Meletzus, D., and Eichenlaub, R. 1997. Characterization of the plasmid encoded virulence region pat-1 of the phytopathogenic Clavibacter michiganensis subsp. michiganensis. Mol. Plant-Microbe Interact. 10:195-206.

10. Echandi, E., and Sun, M. 1973. Isolation and characterization of a bacteriophage for the identification of Corynebacterium michiganense. Phytopathology 63:1398-1401.

11. Eichenlaub, R., and Gartemann, K.-H. 2011. The Clavibacter michiganensis subspecies, molecular investigation of gram-positive bacterial plant pathogens. Annu. Rev. Phytopathol. 49:7.1-7.20.

12. Eichenlaub, R., Gartemann, K.-H., and Burger, A. 2006. Clavibacter michiganensis, a group of gram-positive phytopathogenic bacteria. Pages 385-422 in: Plant-Associated Bacteria. S. S. Gnanamanickam, ed. Springer, Dordrecht, The Netherlands.

13. Evert, R. F. 2006. Esau's Plant Anatomy. John Wiley and Sons Inc., Hoboken, $\mathrm{NJ}$.

14. Gartemann, K.-H., Abt, B., Bekel, T., Burger, A., Engemann, J., Flügel, M., Gaigalat, L., Goesmann, A., Grafen, I., Kalinowski, S., Kaup, O., Kirchner, O., Krause, L., Linke, B., McHardy, A., Meyer, F., Pohle, S., Ruckett, C., Schneiker, S., Zellerman, E.-M., Puhler, A., Eichenlaub, R., Kaiser, O., and Bartels, D. 2008. The genome sequence of the tomatopathogenic actinomycete Clavibacter michiganensis subsp. michiganensis NCPPB382 reveals a large island involved in pathogenicity. J. Bacteriol. 190:2138-2149.

15. Gartemann, K.-H., Kirchner, O., Engemann, J., Gräfen, I., Eichenlaub, R., and Burger, A. 2003. Clavibacter michiganensis subsp. michiganensis: First steps in understanding of virulence of a gram-positive phytopathogenic bacterium. J. Biotechnol. 106:179-191.

16. Herrera, C. M., Koutsoudis, M. D., Wang, X., and von Bodman, S. B. 2008. Pantoea stewartii subsp. stewartii exhibits surface motility, which is a critical aspect of stewart wilt disease development on maize. Mol. Plant-Microbe Interact. 21:1359-1370.

17. Jahr, H., Dreier, J., Meletzus, D., Bahro, R., and Eichenlaub, R. 2000. The endo-beta-1,4-glucanase CelA of Clavibacter michiganensis subsp. michiganensis is a pathogenicity determinant required for induction of bacterial wilt of tomato. Mol. Plant-Microbe Interact. 13:703-714.

18. Kang, Y., Liu, H., Genin, S., Schell, M. A., and Denny, T. P. 2002. Ralstonia solanacearum requires type IV pili to adhere to multiple surfaces and for natural transformation and virulence. Mol. Microbiol. 46:427-437.

19. Kaup, O., Gräfen, I., Zellermann, E. M., Eichenlaub, R., and Gartemann, K.-H. 2005. Identification of tomatinase in tomato pathogenic actinomycete Clavibacter michiganensis subsp. michiganensis NCPPB382. Mol. Plant-Microbe Interact. 18:1090-1098.

20. Kleitman, F., Barash, I., Burger, A., Iraki, N., Sessa, G., Weinthal, D., Chalupowicz, L., Gartemann, K.-H., Eichenlaub, R., and Manulis-Sasson, S. 2008. Characterization of a Clavibacter michiganensis subsp. michiganensis population in Israel. Eur. J. Plant Pathol. 121:463-475.

21. Koczan, J. M., McGrath, M. J., Zhao, Y., and Sundin, G. W. 2009. Contribution of Erwinia amylovora exopolysaccharides amylovoran and levan to biofilm formation: Implications in pathogenicity. Phytopathology 99:1237-1244.

22. Kohlmeier, S., Mancuso, M., Tecon, R., Harms, H., van der Meer, J. R., and Wells, M. 2007. Bioreporters: $g f p$ versus lux revisited and single-cell response. Biosens. Bioelectron. 22:1578-1585.

23. Koutsoudis, M. D., Tsaltas, D., Minogue, T. D., and von Bodman, S. 2006. Quorum-sensing regulation governs bacterial adhesion, biofilm development and host colonization in Pantoea stewartii subspecies stewartii. Proc. Natl. Acad. Sci. USA 103:5983-5988.

24. Meletzus, D., Bermpohl, A., Dreier, J., and Eichenlaub, R. 1993. Evidence for plasmid-encoded virulence factors in the phytopathogenic bacterium Clavibacter michiganensis subsp. michiganensis NCPPB382. J. Bacteriol. 175:2131-2136.

25. Meletzus, D., and Eichenlaub, R. 1991. Transformation of the phytopathogenic bacterium Clavibacter michiganensis subsp. michiganensis by electroporation and development of a cloning vector. J. Bacteriol. 173:184-190.

26. Meng, Y., Li, Y., Galvani, C. D., Hao, G., Turner, J. N., Burr, T. J., and Hoch, H. C. 2005. Upstream migration of Xylella fastidiosa via pilus- 
driven twitching motility. J. Bacteriol. 187:5560-5567.

27. Newman, K. L., Almeida, R. P., Purcell, A. H., and Lindow S. E. 2003. Use of green fluorescence stain for analysis of Xylella fastidiosa colonization of Vitis vinifera. Appl. Environ. Microbiol. 69:73197327.

28. Ramey, B. E., Koutsoudis, M., von Bodman, S. B., and Fuqua, C. 2004. Biofilm formation in plant-microbe interactions. Curr. Opin. Microbiol. 7:602-609.

29. Stork, I., Gartemann, K.-H., Burger, A., and Eichenlaub, R. 2008. A family of serine proteases of Clavibacter michiganensis subsp. michiganensis: $\operatorname{chpC}$ plays a role in colonization of the host plant tomato. Mol. Plant Pathol. 9:599-608.

30. Strider, D. L. 1969. Bacterial canker of tomato caused by Corynebacterium michiganense. A literature review and bibliography. N.C. Agric. Exp. Stn. Tech. Bull. 193
31. Stumpp, T., Wilms, B., and Altenbuchner, J. 2000. Ein neues L-rhamnoseinduzierbares expressions system für Escherichia coli. BIOspektrum I:3336.

32. Sun J., Kelemen G. H., Fernándes-Abalos J. M., and Bibb M. J. 1999. Green fluorescent protein as a reporter for spatial and temporal gene expression in Streptomyces coelicolor A3(2). Microbiology 145:2221-2227.

33. von Bodman, S. B., Bauer, W. D., and Coplin, D. L. 2003. Quorum sensing in plant-pathogenic bacteria. Annu. Rev. Phytopathol. 41:455-482.

34. Wittmann, J., Gartemann, K.-H., Eichenlaub, R., and Dreiseikelmann, B. 2011. Genomic and molecular analysis of phage CMP1 from Clavibacter michiganensis subspecies michiganensis. Bacteriophage 1:1-8.

35. Xu, X., Miller, S. A., Baysal-Gurel, F., Gartemann, K.-H., Eichenlaub, R., and Rajashekara, G. 2010. Bioluminescence imaging of Clavibacter michiganensis subsp. michiganensis infection of tomato seeds and plants. Appl. Environ. Microbiol. 76:3978-3988. 